Jour. Geol. Soc. Japan, Vol. 119, No. 1, 2013

\title{
Ground-penetrating radar imaging of a concealed active fault in the district damaged \\ by the 2011 northern Nagano-ken earthquake, central Japan
}

Takao Miyata* and Tsutomu Otsuka**

* Graduate School of Science, Osaka City University (Visiting Professor), Osaka 558-8585, Japan

** School of General Education, Shinshu University, Matsumoto 390-8621, Japan

Received October 1, 2012.

Accepted November 21, 2012.

The moment magnitude $(M w) 6.3$ northern Nagano-ken earthquake occurred upon an active fault zone along the border between Nagano and Niigata Prefectures after the $M w 9.0$ Tohoku Pacific Ocean earthquake (Fig. 1A). This far-field induced earthquake damaged a number of houses in the Mori, Aokura, and Yokokura Districts of Sakae Village in Nagano Prefecture (Fig. 2) (e.g., Miyata and Otsuka, 2012). The Research Group for Active Faults (1980) proposed the existence of the Aokura Fault in the Aokura District with a II degree of certainty and assigned this fault Class B activity status, with activation around $0.1 \mathrm{~m} / 1,000$ yrs. (Fig. 1B). The fault occurs within a terrace, has a length of more than $3 \mathrm{~km}$, and strikes NE-SW, but with an unknown dip. Drill core data (Fig. 3) indicate that the terrace deposits that host the fault are dominated by thick, silty sands that contain pebble- to cobble-sized clasts.

Ground-penetrating radar (GPR) transmits a high-frequency electromagnetic pulse (10-1,000 MHz) of energy into the ground; this pulse radiates downwards, with some of its energy reflected back to the surface by sedimentary horizons (Fig. 4). We used GPR in this study to identify subsurface structures in August 2011 within the area of the Aokura District damaged by the northern Nagano-ken earthquake.

The presence of an obvious discontinuity and the dragging of reflected signals enabled the identification of three hidden faults in GPR sections (Fig. 5): a main fault (shown as a thick broken line in Fig. 5B) and two subsidiary synthetic and antithetic faults (shown as thin broken lines in Fig. 5B) in the hanging wall of the main fault. The main fault is a low-angle reverse fault with a vertical displacement of about $80 \mathrm{~cm}$, identified using drag directions. In addition, weakly reflected GPR signals define layers (dark reddish to pale greenish layers in Fig. 5) within the footwall of the main fault.

Fig. 1. (A) Index map showing the location of the Eurasian (Eu), Philippine Sea $(\mathrm{Ph})$, and Pacific (Pa) plates, active faults (shown as red lines) (The Research Group for Active Faults, 1980), the epicenter of the 2011 northern Nagano-ken earthquake (shown as a star), and the location of Fig. 1B (shown as a rectangle). (B) Geological map of the Aokura and Mori Districts of Sakae Village, Nagano Prefecture (modified from Takeshita et al., 2012); the ARA-3 survey line is $184 \mathrm{~m}$ long, and the arrow indicates the survey direction. Solid circle indicates the hidden fault location identified using GPR in this study, open circle indicates the location of the Sakae Village Office, and the open square indicates the location of Fig. 3.
Corresponding author; T. Miyata, miyata@kobe-u.ac.jp
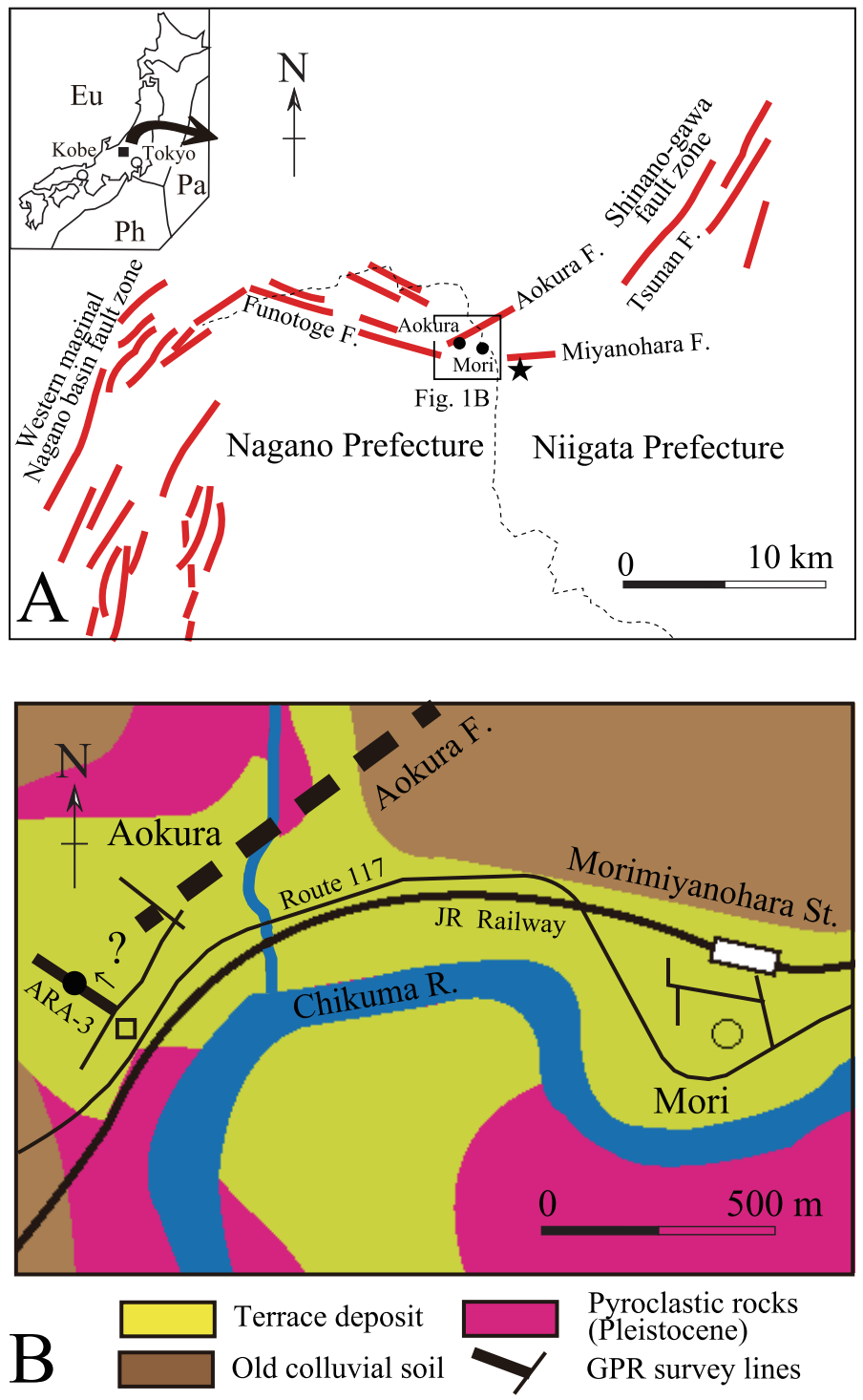

Fig. 2( $\downarrow)$. (A) Houses along a NE-SW-trending road in the Aokura District, Sakae Village, Nagano Prefecture, that were damaged by the 2011 northern Nagano-ken earthquake; photo taken in April 2011. (B) Southward-leaning house in the Aokura District; photo taken in August 2011.
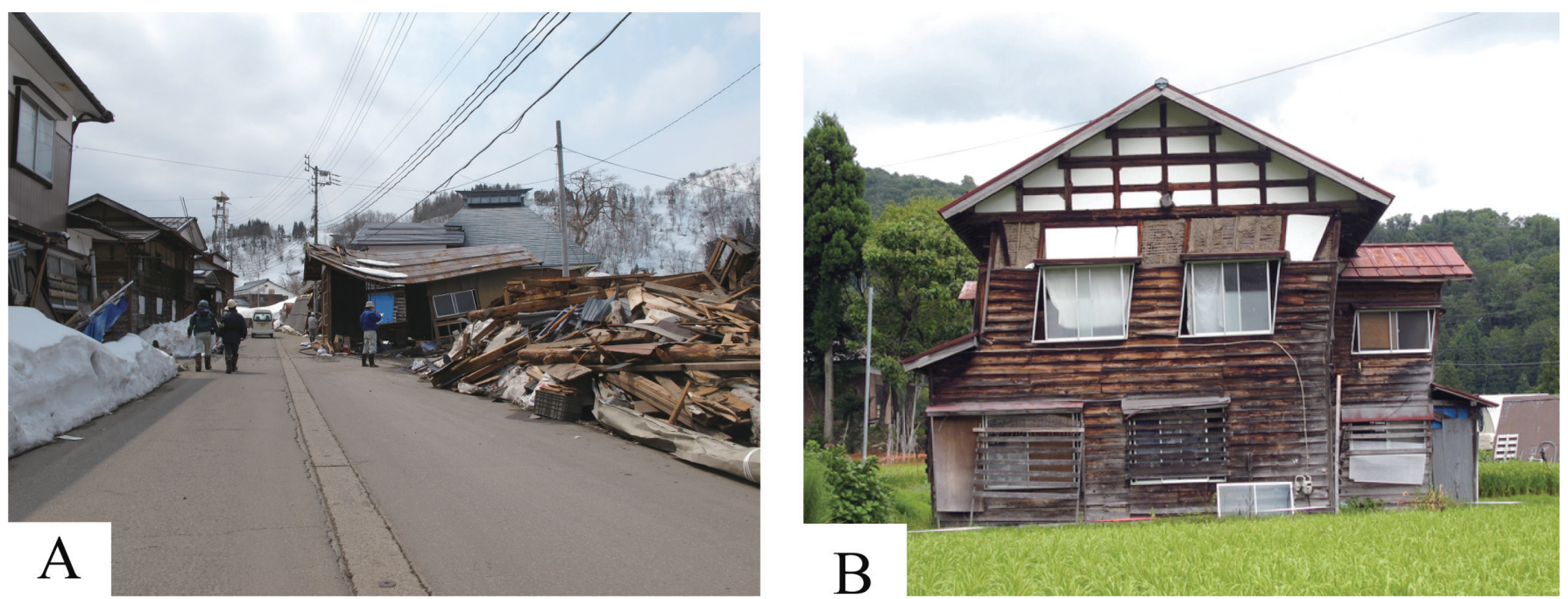


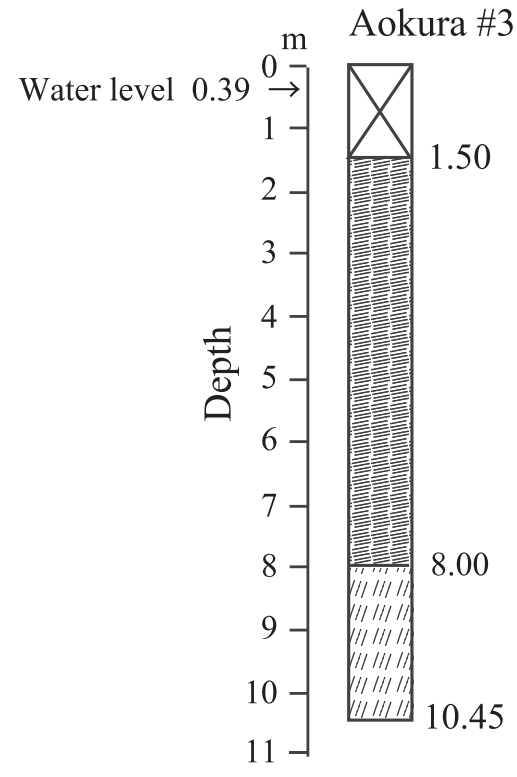

Silty sand containing pebbles

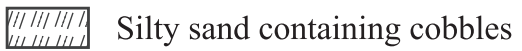

Fig. 3. Aokura \#3 drill-core data of obtained by Sakae Village Office, Nagano Prefecture.

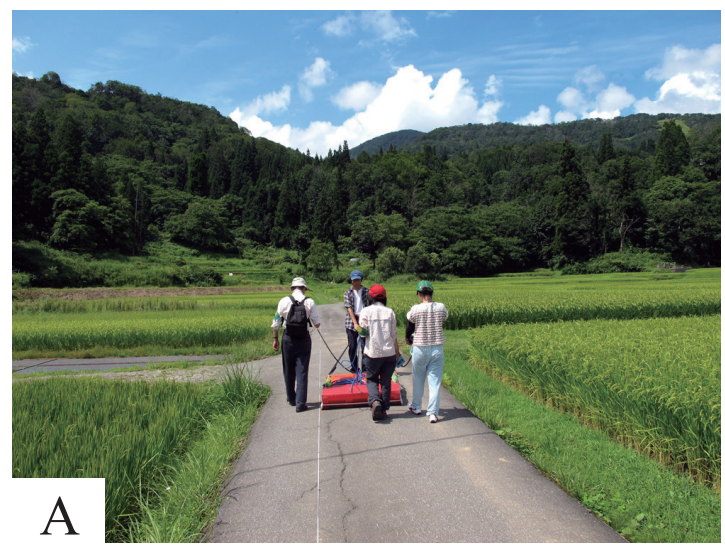

\section{Acknowledgements}

We thank Sakae Village Office for access to drill-core data, Prof. Shoichi Yoshioka (Kobe University), Miss Mayo Nojirino (Kobe City Office), Miss Yuka Yamagishi, and Messrs. Tatsuya Deguchi and Hiroki Hongo (Shinshu University) for assistance during this research, and reviewers for constructive suggestions that have improved this paper. This study was supported by funding from the Research Center for Urban Safety and Security of Kobe University and the Institute of Mountain Science, Shinshu University.

\section{References}

Miyata, T. and Otsuka, T., 2012, Subsurface structures and damages, caused by a far-induced earthquake of the 2011 Tohoku-off Pacific Ocean earthquake, in Sakae Village, Nagano Prefecture. 119th Ann. Meet. Geol. Soc. Japan, Abstr., 572. (in Japanese)

Takeshita, Y., Otsuka, T., Kobayashi, Y., Shiono, T., Tazawa, T., Tanabe, T., Terao, M., Togashi, H., Nakamura, Y., Hanaoka, K. and Miyashita, T., 2012, Relationship among topography, geology and damages caused by the 2011 Northern Nagano-ken Earthquake. Reports of Research on the 2011 Northern Nagano-ken Earthquake, Institute Mountain Science, Shinshu University, 17-30. (in Japanese)

The Research Group for Active Faults, ed., 1980. Active Faults in Japan, Sheet Maps and Inventories. Univ. Tokyo Press, 363p. (in Japanese with English explanation)

Fig. 4( $\downarrow)$. (A) GPR investigations along a NW-SE-trending road across a rice field in the Aokura District. (B) Schematic drawing of a GPR system with antennas; $V=$ Velocity of the GPR wave $(\mathrm{m} / \mathrm{ns})$. The velocity of the wave is related to the relative dielectric permittivity $\varepsilon$, by $V=c / \varepsilon^{1 / 2}$, where $c$ $=$ the velocity of an electromagnetic-wave in free space; velocities in saturated sands and silts are $0.60-0.80 \mathrm{~m} / \mathrm{ns}$. We used a GSSI SIR-3000 GPR control unit and two $100 \mathrm{MHz}$ frequency antennas, with GPR data processed to accentuate geological features using the GSSI RADAN 7 software.

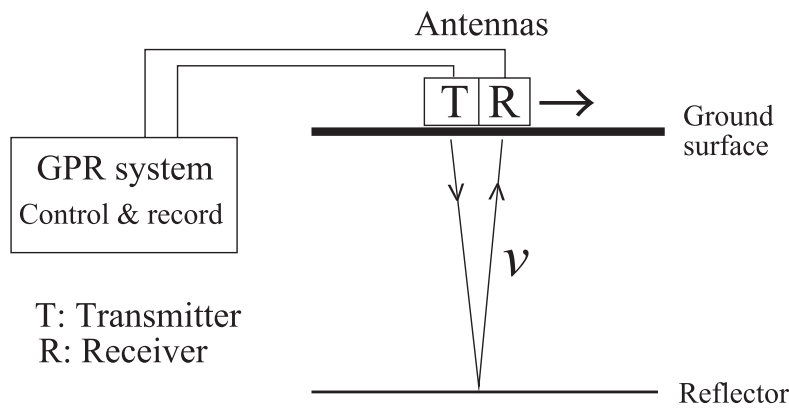

$\mathrm{B}$

Fig. 5( $\downarrow$ ). Hidden faults imaged in GPR sections within the Aokura District of Sakae Village, Nagano Prefecture. (A) GPR section for a travel time of $150 \mathrm{~ns}$ with a color legend identifying reflected signals; times were changed to depths using wide-angle measurements. (B) An interpreted, enlarged GPR section from 77 to $137 \mathrm{~m}$ location, with the main fault identified by reflector discontinuities around $100 \mathrm{~m}$; the drag of these reflectors is located along the hanging wall of the main fault

\section{Location (m)}

signal amplitude

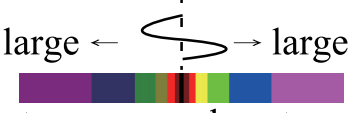

strong $\leftarrow$ weak $\rightarrow$ strong reflected signals

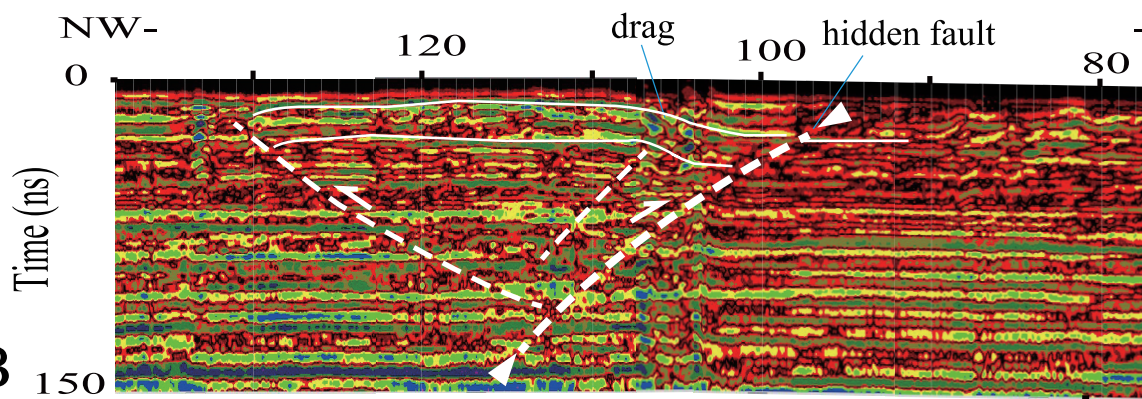

$\mathrm{H}: \mathrm{V}=1: 3.2$
ARA-3_f028_100 MHz

NW- ditch

$$
\text { 吕 }
$$

180 160

\section{Location (m)}

120

100

80

60

40

snow melting facitity

$-\mathrm{SE}$

\section{豆
言
Ф}

5.2

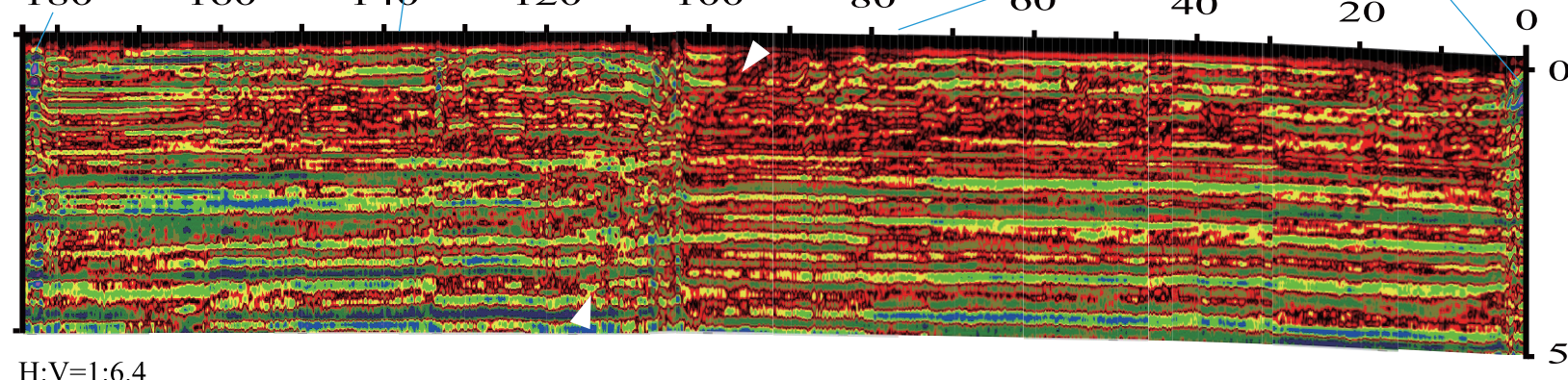

